\title{
Development of a New Research Platform for Electrical Drive System Modelling for Real-Time Digital Simulation Applications
}

\author{
S. Umashankar, ${ }^{1}$ Mandar Bhalekar, ${ }^{1}$ Surabhi Chandra, ${ }^{1}$ \\ D. Vijayakumar, ${ }^{1}$ and D. P. Kothari ${ }^{2}$ \\ ${ }^{1}$ School of Electrical Engineering, VIT University, Vellore 632014, India \\ ${ }^{2}$ MVSR Engineering College, Nadergul, Hyderabad 501510, India \\ Correspondence should be addressed to S. Umashankar; shankarums@gmail.com
}

Received 31 January 2013; Revised 1 June 2013; Accepted 29 June 2013

Academic Editor: Don Mahinda Vilathgamuwa

Copyright (C) 2013 S. Umashankar et al. This is an open access article distributed under the Creative Commons Attribution License, which permits unrestricted use, distribution, and reproduction in any medium, provided the original work is properly cited.

\begin{abstract}
This paper presents the research platform for real-time digital simulation applications which replaces the requirement for full-scale or partial-scale validation of physical systems. To illustrate this, a three-phase AC-DC-AC converter topology has been used consists of diode rectifier, DC link, and an IGBT inverter with inductive load. In this topology, rectifier as well as inverter decoupled and solved separately using decoupled method, which results in the reduced order system so that it is easy to solve the state equation. This method utilizes an analytical approach to formulate the state equations, and interpolation methods have been implemented to rectify the zero-crossing errors, with fixed step size of $100 \mu \mathrm{sec}$ is used. The proposed algorithm and the model have been validated using MATLAB simulation as $\mathrm{m}$-file program and also in real-time DSP controller domain. The performance of the real-time system model is evaluated based on accuracy, zero crossing, and step size.
\end{abstract}

\section{Introduction}

The ever growing complexity and size of electric drives and their related mechanical loads [1] represent an important challenge for those responsible for their testing and verification. The considerations highlight the need for a thorough and exhaustive testing of the controls under conditions that are realistic [2]. For these reasons, it is customary that all controllers for high-power electric drives be tested in controlled laboratory conditions [2].

A recent alternative way of testing that is fast becoming quite popular is to use fully real-time digital simulation. These simulations can also be interfaced with industrial controllers, thus saving a lot of the investment cost and allowing an economic tool for drive controller testing and offering the flexibility needed to simulate machines in all power ranges [2]. The use of virtual system enables relatively easier interface of the drive systems to the computer, and it allows faster "online data and signal processing for analysis purposes." Earlier hardware has been replaced by equivalent simulation model, and the same has been tested using controller, the so-called HIL. Recently, systems tested in real time fully digital simulation with controller as well as hardware using a simulation model [3].

Simulating a drive in real time starts with the problem of modelling the drive, and various works have been made in developing models of drives, most notably those in $[1,2,4]$. The authors of [4] have proposed an interesting alternative to modelling the drives using a state-space model that can easily be implemented using MATLAB, and the parameters can be found from standard theories and tests [4]. Many researchers are doing this research work and found various approximate and optimistic solution approach methods and tested the same. Based on their past experience, a simple method to form state equations involves switching function method [5]. This method involves mathematical modelling of a system rather than a circuit-based modeling and hence does not have the problems mentioned like in PSpice, PSIM [5-7]. Also, this method is defined by its function related to its state rather than its generalized equation. But coupled method suffers from numerical error due to higher order system equations. So, in this work, decoupled method is used which is very 


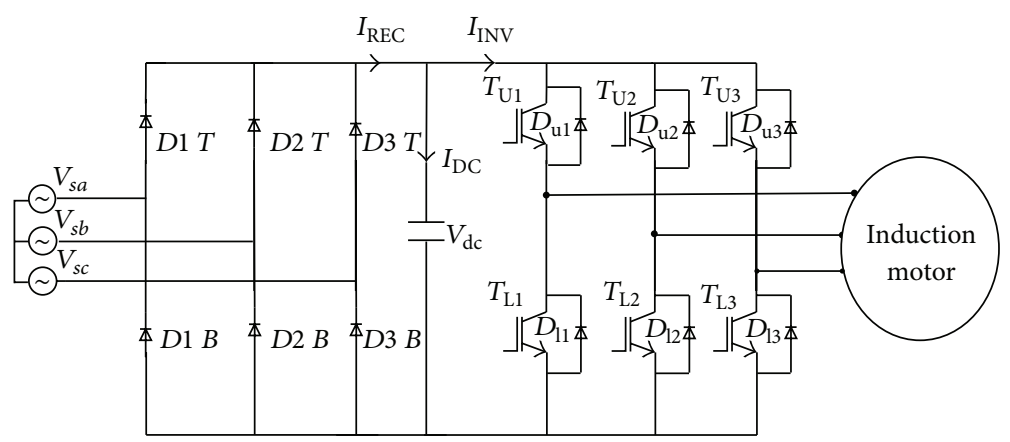

FIGURE 1: Three-phase converter topology with diode rectifier, DC link, and inverter fed IM.

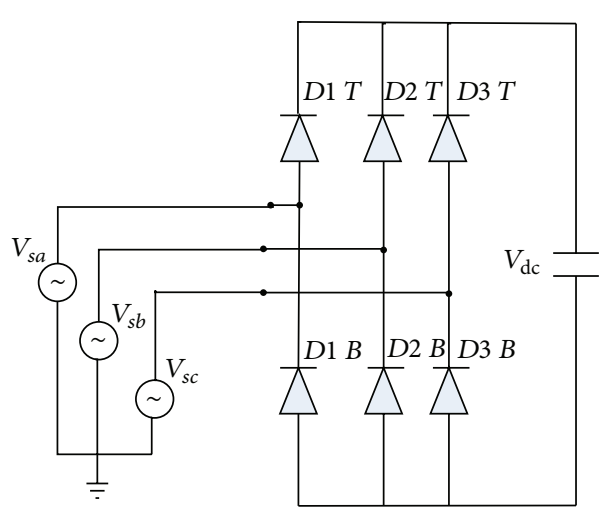

(a)

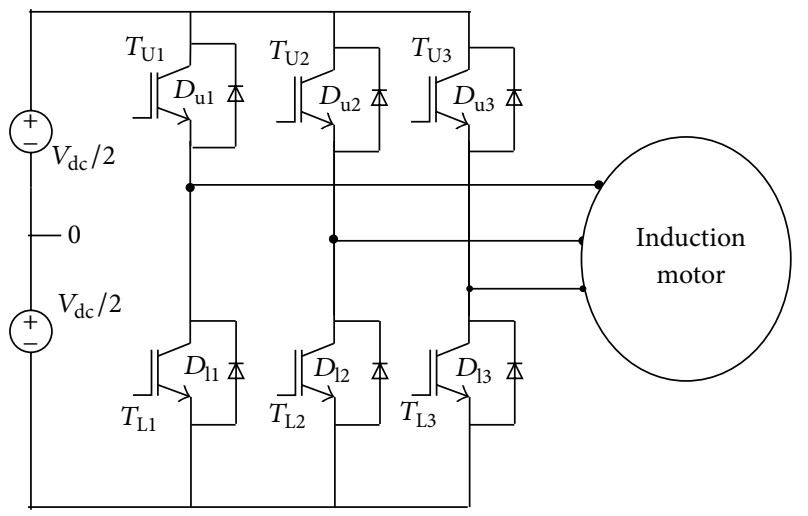

(b)

FIgure 2: (a) Circuit 1: diode rectifier with DC link. (b) Circuit 2: inverter fed induction motor with DC source.

simple and allows developing the analytical equations suitable for any power electronic system by decoupling rectifier and inverter. This also gives exact solution, and error is almost reduced.

In this paper, decoupled method for a simple three-phase DC link inverter fed induction machine is proposed. The topology of the converter considered in this paper comprises diode rectifier, capacitive DC link PWM IGBT inverter, and induction motor as load. Decoupled analytical method is used to solve all the state variables of the earlier test circuit (source current, DC link voltage, and load current) for accurate results. Decoupling is implemented to reduce the system equation order so as to achieve fast calculation and easier to get an analytical expression from solution to state-space equations of the two converters. Performance parameters of the drive system have been validated using MATLAB scripts ( $m$-file) and also on DSP platform. This method has advantages like reduced system order, simplified solution, easier calculation, exact zero crossing, and less data storage due to large step size comparing coupled method.

\section{Methodology}

Figure 1 represents the topology of the power converter to be modelled with decoupled algorithm with zero crossing. In every sampling period of the discrete model, two circuits are considered. The first part of the circuit consists of an AC voltage source having an internal impedance connected to a diode rectifier with a DC link capacitor. The second part is having a constant voltage source in DC link, PWM inverter, and an IM load. At the end of every sampling period, DC link voltage is computed by integrating the difference in rectifier and inverter currents.

The proposed decoupled algorithm to solve the statespace equation of the electric drive system is given later.

Step 1. Initialization parameters of the selected system.

Step 2. Decouple the diode bridge rectifier and inverter fed induction motor circuit.

Step 3. Define different cases with an equivalent circuit for two decoupled circuits.

Step 4. Assume that $V_{\mathrm{dc} 0}$ is a known value (initial value $=0$ ).

Step 5. Solve state-space equation of the diode bridge rectifier, and find rectifier side DC link current $\left(I_{\mathrm{REC}}\right)$ using analytical/numerical method based on its switching states/function.

Step 6. Solve state-space equation of inverter fed induction motor, and find inverter side DC links current $\left(I_{\mathrm{INV}}\right)$ using analytical/numerical method based on its switching states/function (see Figure 2). 


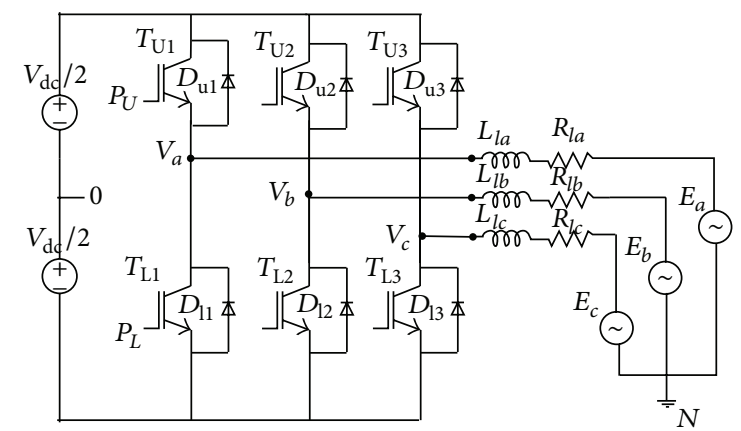

FIGURE 3: IGBT-diode inverter circuit with equivalent induction motor.

Step 7. Find capacitor current $I_{\mathrm{DC}_{n+1}}$ using rectifier and inverter side DC link currents from Steps 5 and 6, respectively.

Step 8. Solve the differential equation of DC link current, and find $V_{\mathrm{DC}_{n+1}}$ using analytical/numerical method.

Step 9. Repeat the iteration for all cases up to stop time.

Step 10. Compare with offline simulation results using Simulink/Simulation tool:

$$
\begin{aligned}
& I_{\mathrm{REC}_{n+1}}=(\left(0.5 *\left(1+\operatorname{sign}\left(I_{a s_{n+1}}\right) * I_{a s_{n+1}}\right)\right. \\
&+\left(0.5 *\left(1+\operatorname{sign}\left(I_{b s_{n+1}}\right)\right) * I_{b s_{n+1}}\right) \\
&+\left.\left.\left(0.5 *\left(1+\operatorname{sign}\left(I_{c s_{n+1}}\right)\right) * I_{c s_{n+1}}\right)\right)\right), \\
& I_{\mathrm{INV}_{n+1}}=0.5 *\left(\left(I_{T U 1}+I_{D U 1}\right)-\left(I_{T L 1}+I_{D L 1}\right)\right. \\
&+\left(I_{T U 2}+I_{D U 2}\right)-\left(I_{T L 2}+I_{D L 2}\right) \\
&\left.+\left(I_{T U 3}+I_{D U 3}\right)-\left(I_{T L 3}+I_{D L 3}\right)\right) .
\end{aligned}
$$

The equation for diode rectifier side DC link current component is obtained by using individual diode currents shown in (1), where $I_{\mathrm{IREC}_{n+1}}$ is rectifier side DC component of current at $n+1$ sample and $I_{a s 1}, I_{b s 1}$, and $I_{c s 1}$ are $(n+1)$ th sample of source side currents of Phase, $(a),(b)$, and $(c)$, respectively, in Inverter.

The equation for inverter side DC link current component is obtained by using individual switch currents and diode currents shown in (2), where $I_{\mathrm{INV}_{n+1}}$ is inverter side DC Component of DC link current at $(n+1)$ th sample, $I_{T U 1}, I_{T U 2}$, and $I_{T U 3}$ are $n$th sample of upper switch currents, and $I_{T L 1}, I_{T L 2}$, and $I_{T L 3}$ are $(n+1)$ th sample of lower switch currents of phases $(a),(b)$, and $(c)$, respectively, in Inverter:

$$
I_{\mathrm{DC}_{n+1}}=I_{\mathrm{REC}_{n+1}}-I_{\mathrm{INV}_{n+1}},
$$

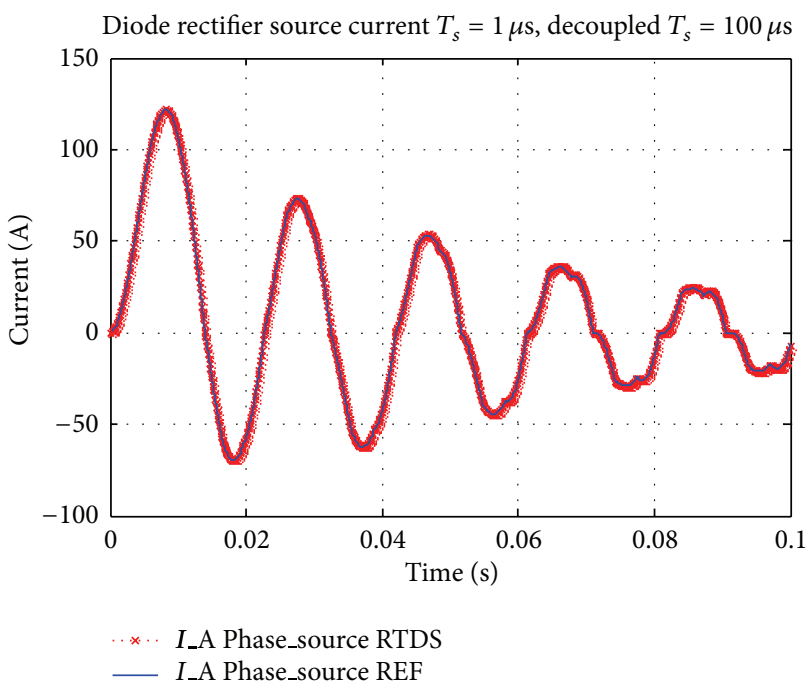

FIGURE 4: Diode rectifier side source current in phase A for both REF (blue trace) and RTDS (red traces).

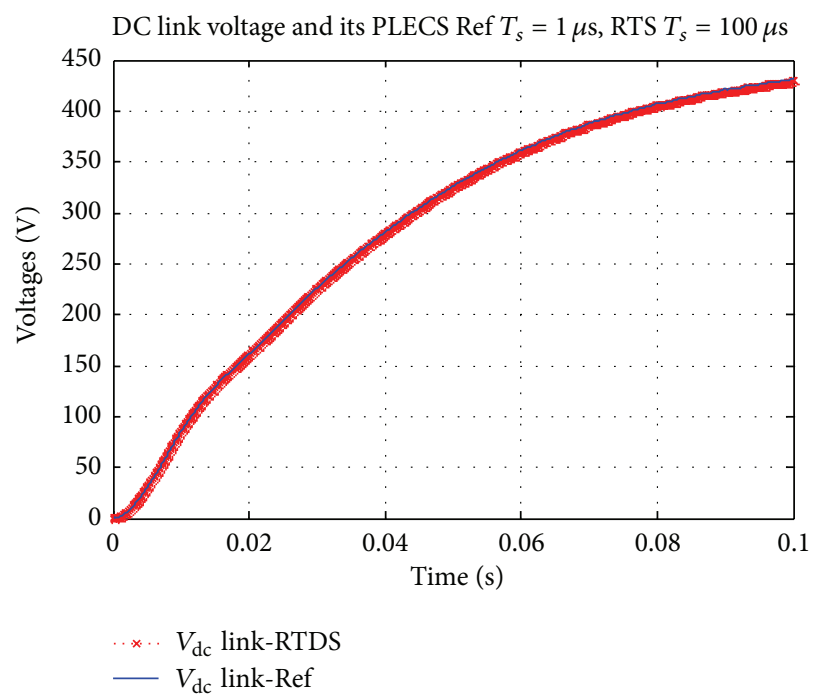

FIGURE 5: DC link voltage REF (blue trace), RTDS (red trace).

where $I_{\mathrm{DC}_{n+1}}$ is capacitor current at $n+1$ sample.

From (3), DC link voltage of $(n+1)$ th sample can be calculated as.

$$
V_{\mathrm{DC}_{n+1}}=V_{\mathrm{DC}_{n}}+\left(\frac{h}{C_{\mathrm{dc}}}\right) * I_{\mathrm{DC}_{n+1}}
$$

This sample is used to formulate the four different cases and its switching logic for an inverter circuit explained in Section 3 for identifying all these parameters for next iteration or time step.

\section{Modelling of IGBT-Diode Inverter and Induction Machine}

Consider the IGBT-diode inverter circuit as in Figure 3 with induction machine load. Assume that two DC link voltages 
are equal $\left(V_{\mathrm{dc}} / 2\right.$ each). Then, voltage at the DC link midpoint is at zero potential. Similarly, $E a, E b$, and $E c$ are considered to be back emf of induction machine in each phase, and " $N$ " is the neutral point of the induction machine stator windings. Let us assume that $V_{a 0}, V_{b 0}$, and $V_{c 0}$ are the pole voltages of each phase leg.

Consider only that phases leg $\mathrm{A}$ and $P_{U}, P_{L}$ are the PWM pulses to upper $\left(\mathrm{T}_{U 1}\right)$ and lower $\left(\mathrm{T}_{L 1}\right)$ IGBT switches. If we define modes of operation for the phase leg A alone by considering its state variables and PWM sequences, we arrive at four different examples as given in what follows.

Case 1. $\left(P_{U}=1 ; P_{L}=0\right)$ upper IGBT switches on condition

$$
\begin{aligned}
& \underline{\left(\left(\left(0.5 \cdot V_{\mathrm{dc}}-E_{x}\right)>0\right) \& \&\left(\left(P_{u}-P_{l}\right)==1\right)\right.} \| \underline{\left.\left((I<0) \& \& \underline{\left(R . I+L\left(\frac{I-I_{D u}}{H}\right)+E_{x}+V_{N O}\right)}>0.5 V_{\mathrm{dc}}\right)\right)} \\
& I_{T U}=\frac{(1+\operatorname{sign}(I))}{2} * P_{U} I, \quad I_{D U}=\frac{(1-\operatorname{sign}(I))}{2} *\left(1-P_{L}\right) I, \\
& V_{x o}=\left(P_{u}-P_{L}\right) \cdot \frac{V_{\mathrm{dc}}}{2}
\end{aligned}
$$

Case 2. $\left(P_{U}=0 ; P_{L}=1\right)$ lower IGBT switches on condition

$$
\begin{gathered}
\frac{\left(\left(\left(-0.5 \cdot V_{\mathrm{dc}}-E_{x}\right)>0\right) \& \&\left(\left(P_{u}-P_{l}\right)==-1\right)\right.}{\|} \frac{\left(( I > 0 ) \& \& \left(\underline{\left.\left.\left(R \cdot I+L\left(\frac{I-I_{D u}}{H}\right)+E_{x}+V_{N O}\right)>-0.5 V_{\mathrm{dc}}\right)\right)}\right.\right.}{I_{T L}=\frac{(1-\operatorname{sign}(I))}{2} * P_{L} I, \quad I_{T U}=\frac{(1+\operatorname{sign}(I))}{2} *\left(1-P_{U}\right) I,} \\
V_{x o}=\left(P_{u}-P_{L}\right) \cdot \frac{V_{\mathrm{dc}}}{2} .
\end{gathered}
$$

Case 3. $\left(P_{U}=1 ; P_{L}=1\right)$ shorted leg mode

$$
I_{x n+1}=I_{x n} \exp \left(-\frac{t}{T}\right)
$$

Case 4. $\left(P_{U}=0 ; P_{L}=0\right)$ diode bridge mode IGBT switches off condition.

Case 4.1. If

$$
\begin{gathered}
\frac{\left(\underline{\left(E_{x}+V_{N O}\right)}>0.5 V_{\mathrm{dc}}\right)}{}, \\
I_{D U}=I, \\
I_{T U}=0, \\
V_{x o}=\frac{V_{\mathrm{dc}}}{2} .
\end{gathered}
$$

Case 4.2. If

$$
\begin{gathered}
\left.\frac{\left(\left(E_{x}+V_{N O}\right)\right.}{}>-0.5 V_{\mathrm{dc}}\right) \\
I_{D U}=I, \\
I_{T U}=0, \\
V_{x o}=-\frac{V_{\mathrm{dc}}}{2} .
\end{gathered}
$$

Case 4.3. If

$$
\begin{gathered}
\frac{\left(\underline{\left|E_{x}+V_{N O}\right|}<0.5 V_{\mathrm{dc}}\right)}{I_{D U}}=0, \\
I_{T U}=0, \\
V_{x o}=0,
\end{gathered}
$$

where $P_{U}$ is PWM pulse to upper switch; $P_{L}$ is PWM pulse to lower switch; $x$ are phases $(a),(b)$, and $(c)$; and $I$ is induction machine current in $(a),(b)$, and $(c)$ reference frames. 


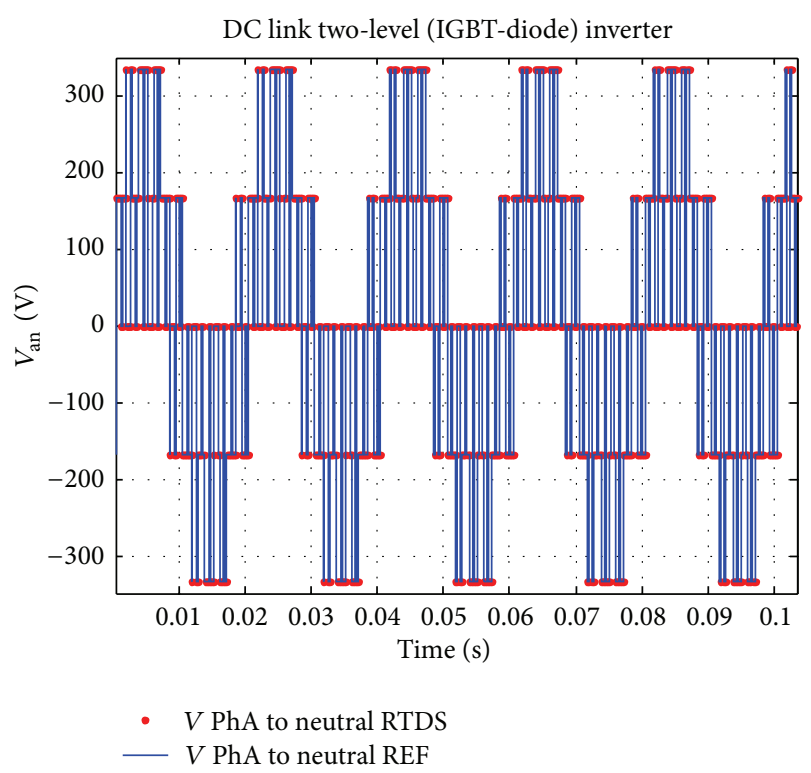

FIGURE 6: Inverter phase A neutral (Van) voltage REF (blue trace), RTDS (red traces).

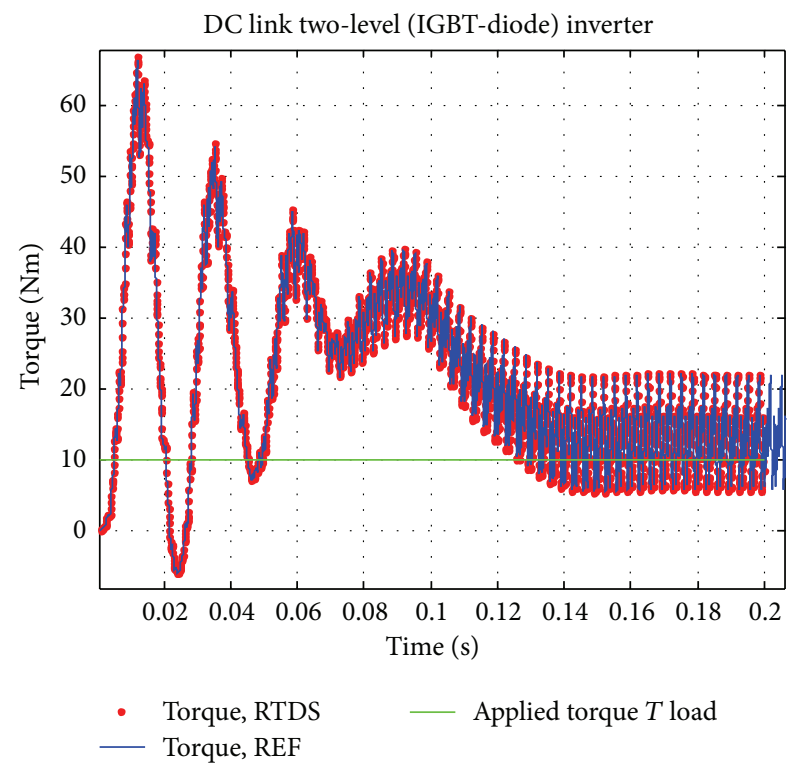

FIGURE 7: Torque developed REF (blue trace), RTDS (red trace).

The logic for two IGBT switches in phase " $a$ " is given in what follows based on the conditions given previously as per four different cases:

$$
\begin{gathered}
T_{\text {ua } 1}=\left(\left(\left(\operatorname{Sign}\left(I_{\text {sa0 }}\right)=1\right) \|\left(I_{\text {sa } 0}=0\right)\right) \& \&\right. \\
\left(\left(\left(0.5 * V_{\mathrm{dc} 0}-V_{\text {nn } 00}\right) \geq 0\right) \& \&\right. \\
\left.\left.\left(P_{u a 1}-P_{l a 1}\right)=1\right)\right),
\end{gathered}
$$

$$
\begin{gathered}
T_{l a 1}=\left(\left(\left(\operatorname{Sign}\left(I_{s a 0}\right)=-1\right) \|\left(I_{s a 0}=0\right)\right) \& \&\right. \\
\left(\left(\left(-0.5 * V_{\mathrm{dc} 0}-V_{n n 00}\right) \leq 0\right) \& \&\right. \\
\left.\left.\left(P_{u a 1}-P_{l a 1}\right)=-1\right)\right) .
\end{gathered}
$$

Similar logic for other two phases $(b)$ and $(c)$ is obtained by replacing the subscript " $a$ " in earlier two equations by " $b$ " and "c." Switching logic for the diode is explained in detail in [8] and hence has not been given here. Similarly, switching function logic for IGBT-diode combination from individual IGBT logic and Diode logic is given later for all the switches in upper legs and lower legs.

Phase leg A top switches on (either IGBT or diode):

$$
\begin{gathered}
S_{u a 1}=T_{u a 1} \| D_{u a 1}, \\
S_{l a 1}=T_{l a 1} \| D_{l a 1} .
\end{gathered}
$$

Phase leg B top switches on (either IGBT or diode):

$$
\begin{gathered}
S_{u b 1}=T_{u b 1} \| D_{u b 1}, \\
S_{l b 1}=T_{l b 1} \| D_{l b 1} .
\end{gathered}
$$

Phase leg C top switches on (either IGBT or diode):

$$
\begin{gathered}
S_{u c 1}=T_{u c 1} \| D_{u c 1}, \\
S_{l c 1}=T_{l c 1} \| D_{l c 1} .
\end{gathered}
$$

Phase to DC link midpoint voltage is given by

$$
\begin{aligned}
& V_{a 01}=0.5 * V_{\mathrm{d} c 0} *\left(S_{u a 1}-S_{l a 1}\right), \\
& V_{b 01}=0.5 * V_{\mathrm{d} c 0} *\left(S_{u b 1}-S_{l b 1}\right), \\
& V_{c 01}=0.5 * V_{\mathrm{dc} 0} *\left(S_{u c 1}-S_{l c 1}\right) .
\end{aligned}
$$

Machine side of each phase voltage is given by

$$
\begin{gathered}
V_{a n 1}=\left(\frac{1}{3}\right) *\left(2 * V_{a 01}-V_{b 01}-V_{c 01}\right), \\
V_{b n 1}=\left(\frac{1}{3}\right) *\left(-V_{a 01}+2 * V_{b 01}-V_{c 01}\right), \\
V_{c n 1}=\left(\frac{1}{3}\right) *\left(-V_{a 01}-V_{b 01}+2 * V_{c 01}\right) .
\end{gathered}
$$

Voltages $V_{a n 1}, V_{b n 1}$, and $V_{c n 1}$, in the previously equation are used as an input stator voltage for induction motor. In order to find the various electrical and mechanical parameters like speed, flux, and current through stator terminals, a simplified or reduced order model has to be developed which has been explained in detail later.

While modelling induction machine, the order of the system plays an important role in real-time simulation [9]. In general, induction machine is modelled in two-phase reference frame. Sometimes this leads to more state matrix parameters and more computation time. At the same time, if it is modelled as the lowest order system, then the state 
variables may deviate from its actual values; this leads to poor accuracy and instability. In order to compromise between accuracy and computation time, the induction machine is modelled in stationary two-phase reference frame $(\alpha-\beta)$ which satisfies the previous criteria. This model has advantages like fewer matrix parameters calculation, preservation of symmetry of the induction machine model state matrix, and minimization of computation time $[9,10]$.

Induction machine model in $\alpha-\beta$ reference frame is as follows:

$$
\begin{gathered}
\frac{d}{d t} \bar{X}(t)=\left[A_{c}(\omega)\right] \bar{X}(t)+\left[B_{c}\right] \bar{U}(t), \\
\bar{Y}(t)=\left[C_{c}\right] \bar{X}(t),
\end{gathered}
$$

where the input vector $[U(t)]$ is chosen to be the reference $\alpha-\beta$ stator voltages, $[X(t)]$ is the $\alpha-\beta$ stator and rotor flux state vector (input), $[Y(t)]$ is the $\alpha-\beta$ stator and rotor current output vector (output), and $\left[A_{c}(\omega)\right],\left[B_{c}\right]$, and $\left[C_{c}\right]$ are state matrix, input matrix, and output matrix, respectively.

As per the reference from $[9,10]$, induction machine equation in $\alpha$ - $\beta$ is expressed in complete form as shown in what follows:

$$
\frac{d}{d t}\left[\begin{array}{c}
\varphi_{s \alpha} \\
\varphi_{s \beta} \\
\varphi_{r \alpha} \\
\varphi_{r \beta}
\end{array}\right]
$$

$$
\begin{aligned}
& =\left[\begin{array}{cccc}
\frac{-R s}{\sigma L s} & 0 & \frac{(1-\sigma) R s}{\sigma M_{s r}} & 0 \\
0 & \frac{-R s}{\sigma L s} & 0 & \frac{(1-\sigma) R s}{\sigma M_{s r}} \\
\frac{(1-\sigma)}{\sigma M_{s r}} R r & 0 & \frac{-R r}{\sigma L r} & -p \omega \\
0 & \frac{(1-\sigma)}{\sigma M_{s r}} R r & p \omega & \frac{-R r}{\sigma L r}
\end{array}\right] \\
& \times\left[\begin{array}{c}
\varphi_{s \alpha} \\
\varphi_{s \beta} \\
\varphi_{r \alpha} \\
\varphi_{r \beta}
\end{array}\right]+\left[\begin{array}{ll}
1 & 0 \\
0 & 1 \\
0 & 0 \\
0 & 0
\end{array}\right]\left[\begin{array}{c}
v_{s \alpha} \\
v_{s \beta}
\end{array}\right], \\
& {\left[\begin{array}{c}
i_{s \alpha} \\
i_{s \beta} \\
i_{r \alpha} \\
i_{r \beta}
\end{array}\right]=\left[\begin{array}{cccc}
\frac{1}{\sigma L s} & 0 & \frac{-(1-\sigma)}{\sigma M_{s r}} & 0 \\
0 & \frac{1}{\sigma L s} & 0 & \frac{-(1-\sigma)}{\sigma M_{s r}} \\
\frac{-(1-\sigma)}{\sigma M_{s r}} & 0 & \frac{1}{\sigma L r} & -p \omega \\
0 & \frac{-(1-\sigma)}{\sigma M_{s r}} & p \omega & \frac{1}{\sigma L r}
\end{array}\right]} \\
& \times\left[\begin{array}{c}
\varphi_{s \alpha} \\
\varphi_{s \beta} \\
\varphi_{r \alpha} \\
\varphi_{r \beta}
\end{array}\right],
\end{aligned}
$$

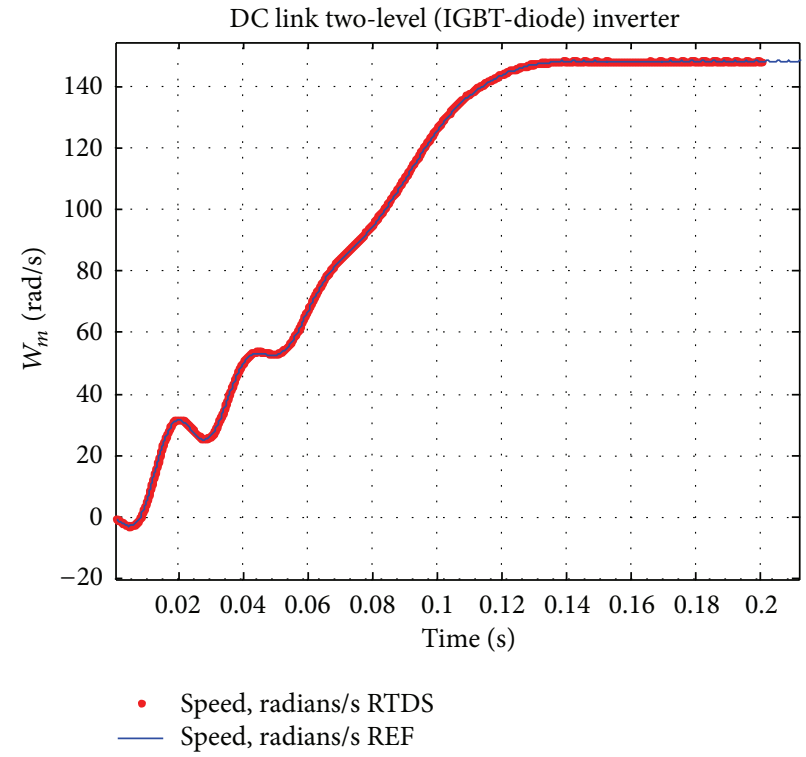

FIGURE 8: Rotor speed in rad/s REF (blue trace), RTDS (red trace).

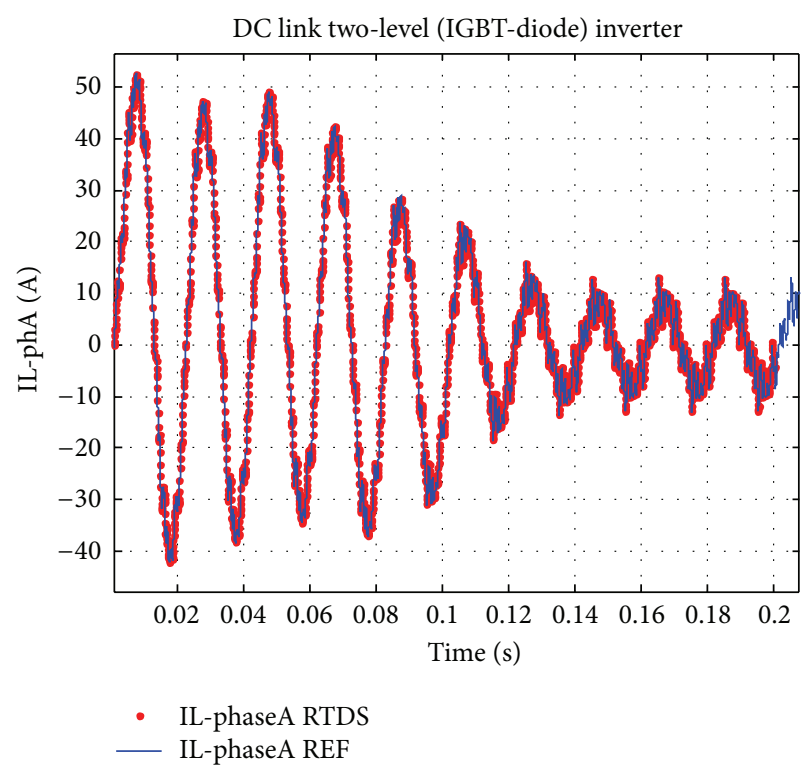

FIGURE 9: Stator ph-A current REF (blue trace), RTDS (red trace).

$$
\begin{aligned}
{\left[\begin{array}{c}
i_{s \alpha} \\
i_{s \beta} \\
\varphi_{r \alpha} \\
\varphi_{r \beta}
\end{array}\right]^{n+1}=} & {\left[\begin{array}{llll}
g 11 & g 12 & g 13 & g 14 \\
g 21 & g 22 & g 23 & g 24 \\
g 31 & g 32 & g 33 & g 34 \\
g 41 & g 42 & g 43 & g 44
\end{array}\right] } \\
& \times\left[\begin{array}{c}
i_{s \alpha} \\
i_{s \beta} \\
\varphi_{r \alpha} \\
\varphi_{r \beta}
\end{array}\right]^{n}+\left[\begin{array}{ll}
h 11 & h 12 \\
h 21 & h 22 \\
h 31 & h 32 \\
h 41 & h 42
\end{array}\right]\left[\begin{array}{l}
V_{s \alpha} \\
V_{s \beta}
\end{array}\right]^{n},
\end{aligned}
$$

where $\sigma=1-\left(M_{s r}^{2} / L_{s} L_{r}\right), p=$ no. of pole pairs in a machine, and $\omega=$ speed in $\mathrm{rad} / \mathrm{s}$. 


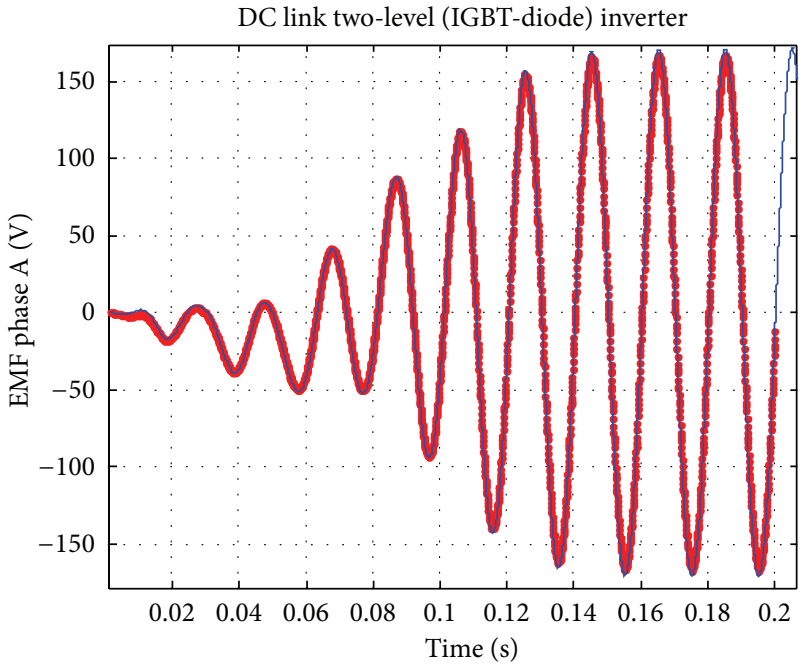

- EMF phase A, RTDS

FIgURE 10: Stator ph-A back EMF-REF (blue trace), RTDS (red trace).

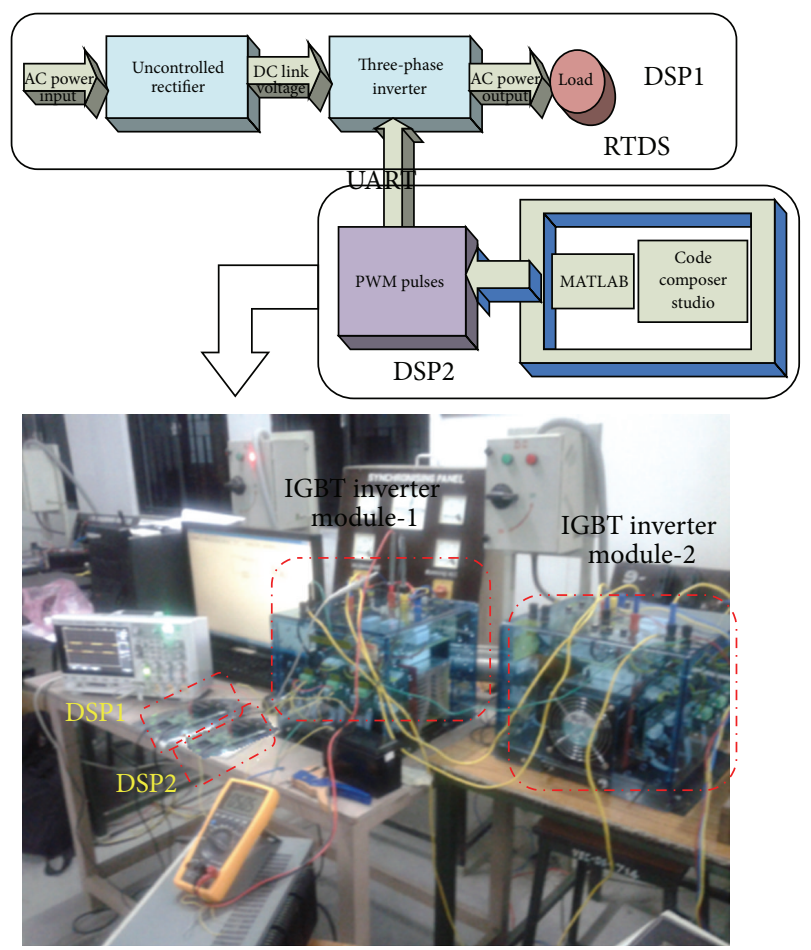

FIGURE 11: Block diagram and snapshot of hardware setup.

In order to find back emf set $i_{s \alpha}=0$ and $i_{s \beta}=0$. Then $E_{s \alpha}=V_{s \alpha}, E_{s \beta}=V_{s \beta}$

$$
\begin{aligned}
{\left[\begin{array}{l}
E_{s \alpha} \\
E_{s \beta}
\end{array}\right]^{n}=} & \frac{-1}{(h 11 \cdot h 22-h 21 \cdot h 12)}\left[\begin{array}{cc}
h 22 & -h 12 \\
-h 21 & h 11
\end{array}\right] \\
& \times\left[\begin{array}{ll}
g 13 & g 14 \\
g 23 & g 24
\end{array}\right]\left[\begin{array}{l}
\varphi_{r \alpha} \\
\varphi_{r \beta}
\end{array}\right]^{n},
\end{aligned}
$$

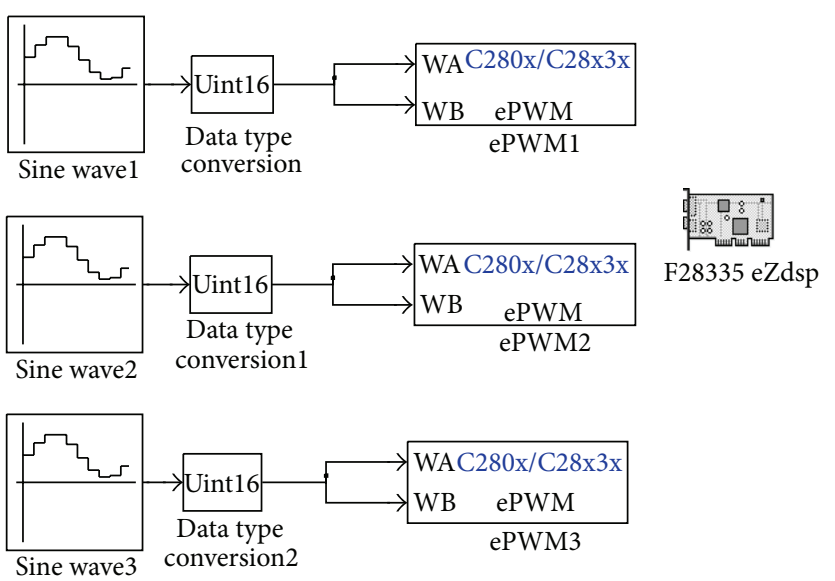

FIGURE 12: DSP interface for PWM pulse generation.

TABLE 1: Input parameters for RTDS and Simulink-PLECS.

\begin{tabular}{lcc}
\hline Source parameters & DC link inverter & Load parameters \\
\hline $\mathrm{Vm}=1.414 * 220 ;$ & $\mathrm{Cdc}=10 \mathrm{mF}$ & \\
$f=50 ;$ & $\mathrm{Fsw}=450 \mathrm{~Hz}$ & As given in Table 3 \\
$\omega=2 *$ pi $* f ;$ & $H=100 e-6 \mathrm{~s}$ & \\
$\mathrm{Rs}=1 \Omega$ & $m=0.8$ & \\
$\mathrm{Ls}=10 \mathrm{mH}$ & & \\
\hline
\end{tabular}

where $g_{m n}, h_{m n}$ are the state and input matrix coefficients of the stationary reference frame model of induction machine. At every sampling time, stator currents have been calculated using stator voltages, and finally back emf of each phase has been calculated as per (19). Current sample of back emf has been used for the next iteration to identify the mode of operation of inverter given in Section 3. With these equations, a generalized model of the complete electrical drive system has been developed and validated with offline SimulinkPLECS model given later.

\section{Simulation Results}

Input parameters for proposed model as well as for SimulinkPLECS (REF) offline simulation are shown in Table 1.

4.1. Offline Results versus Real-Time Digital Simulator. In this case, simulations are carried out with both rectifier and inverter now decoupled at DC link. Both circuits are treated as separate circuits, and rectifier current with DC link and inverter current with DC link are calculated separately. At the end of the iteration, DC link voltage will be updated using the rectifier and inverter currents.

In Figures 4, 5, 6, 7, 8, 9, and 10, red trace is from Simulink-PLECS reference results which are overplotted on that of RTDS-decoupled solution. From Figures $4-10$, it is very clear that proposed real-time model and offline Simulink results are matching each other in terms of accuracy as well as with larger step size of $100 \mu$ s proposed model with the $1 \mu \mathrm{s}$ Simulink reference model.

Table 2 shows that at a particular time of sample, electrical and mechanical parameters of real-time electrical drive 

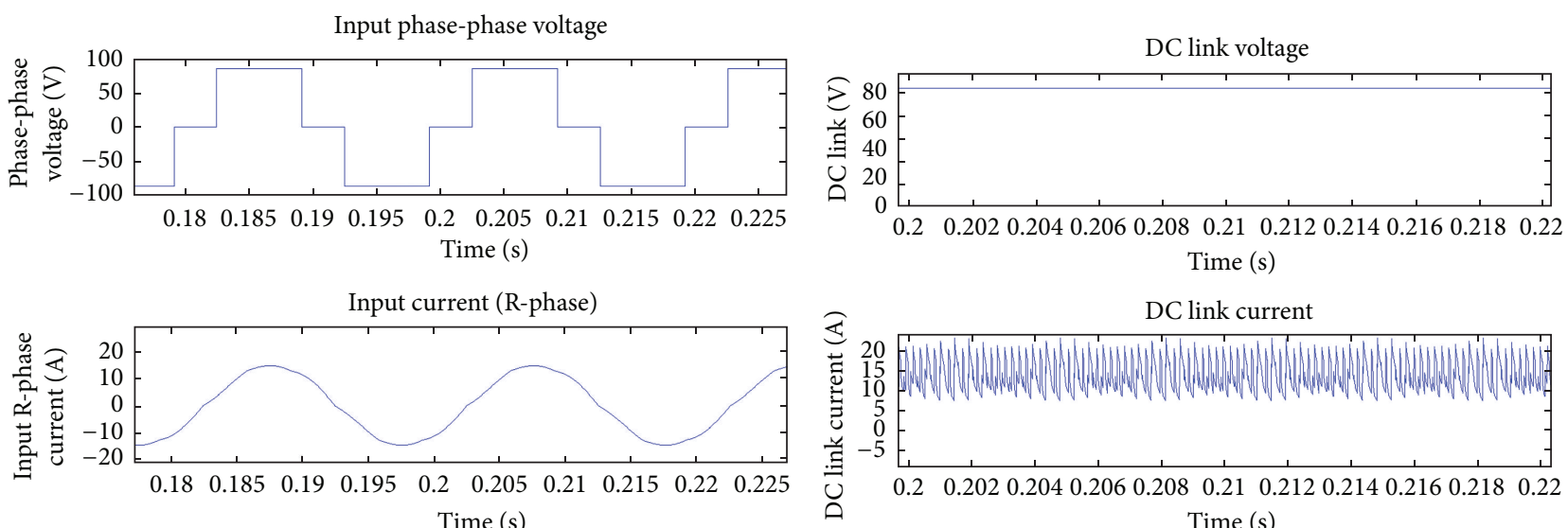

(a)

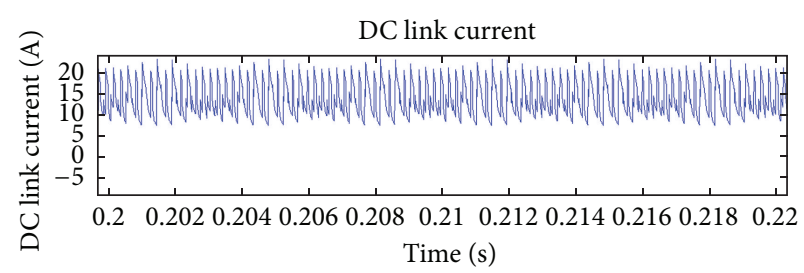

(b)
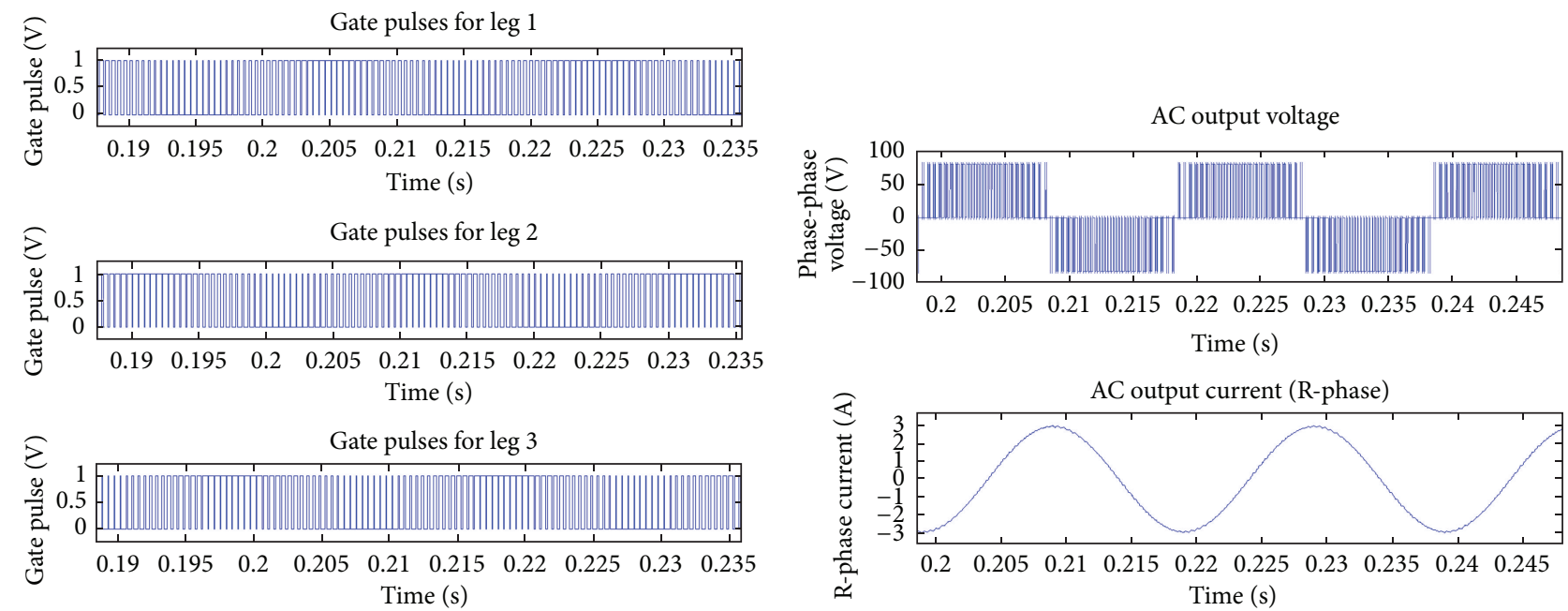

(c)

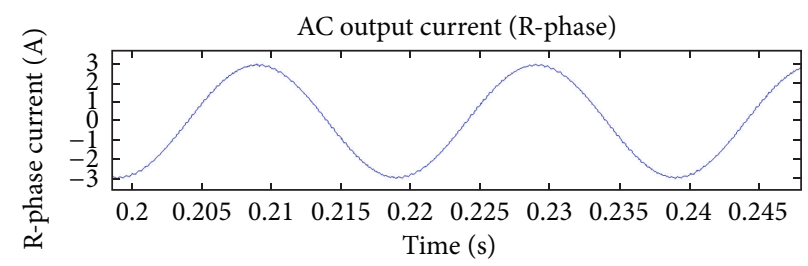

(d)

FIGURE 13: Proposed mathematical model offline results showing (a) input voltage (ph-ph) and current (R-phase), (b) DC link voltage and current, (c) PWM pulses for 3 legs of inverter, and (d) output voltage (ph-ph) and current (R-Phase).

TABLE 2: Comparison of proposed real-time digital simulator results with Simulink-PLECS offline results.

\begin{tabular}{|c|c|c|c|c|c|}
\hline S. no. & Parameter & Time of sample & $\begin{array}{l}\text { Reference } \\
\text { Simulink- } \\
\text { PLECS } \\
\text { (a) }\end{array}$ & $\begin{array}{l}\text { Proposed RTDS } \\
\text { solution } \\
(b)\end{array}$ & $\begin{array}{l}\text { Percentage of error (\%) } \\
\qquad((b)-(a)) /(a)\end{array}$ \\
\hline \multirow{2}{*}{1} & \multirow{2}{*}{ DC link voltage $\mathrm{V}$} & 0.01 & 85.46 & 85.88 & $0.491 \%$ \\
\hline & & 0.102 & 500.1 & 500.9 & $0.1 \%$ \\
\hline \multirow{2}{*}{2} & \multirow{2}{*}{ Rectifier source current in phase A Amps } & 0.008 & 121.5 & 121.4 & $-0.082 \%$ \\
\hline & & 0.086 & 24.18 & 24.71 & $2.19 \%$ \\
\hline \multirow{2}{*}{3} & \multirow{2}{*}{ Stator current in phase A Amps } & 0.009512 & 51.95 & 51.8 & $-0.00288 \%$ \\
\hline & & 0.08951 & 5.596 & 5.55 & $-0.00822 \%$ \\
\hline \multirow{2}{*}{4} & \multirow{2}{*}{ Inverter line to neutral voltage van (V) } & 0.009512 & 333.3 & 333.3 & $0 \%$ \\
\hline & & 0.08951 & 333.3 & 333.3 & $0 \%$ \\
\hline \multirow{2}{*}{5} & \multirow{2}{*}{ Electromagnetic torque tem $(\mathrm{N}-\mathrm{m})$} & 0.01186 & 66.33 & 66.86 & $0.7 \%$ \\
\hline & & 0.1985 & 22.02 & 22.02 & $0.0 \%$ \\
\hline \multirow{2}{*}{6} & \multirow{2}{*}{ Rotor speed $\omega(\mathrm{rad} / \mathrm{s})$} & 0.02 & 31.41 & 31.71 & $0.9 \%$ \\
\hline & & 0.1922 & 148.48 & 148.51 & $0.02 \%$ \\
\hline
\end{tabular}




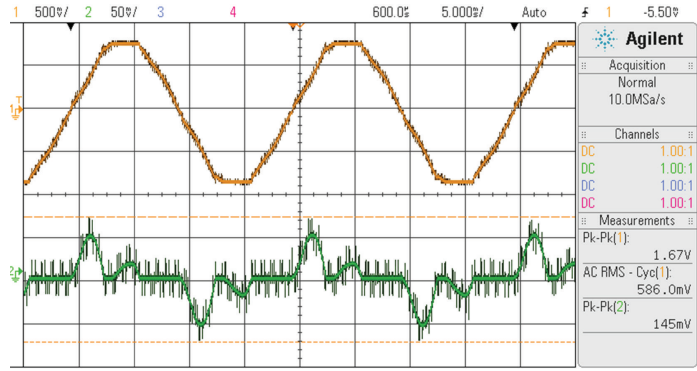

(a)

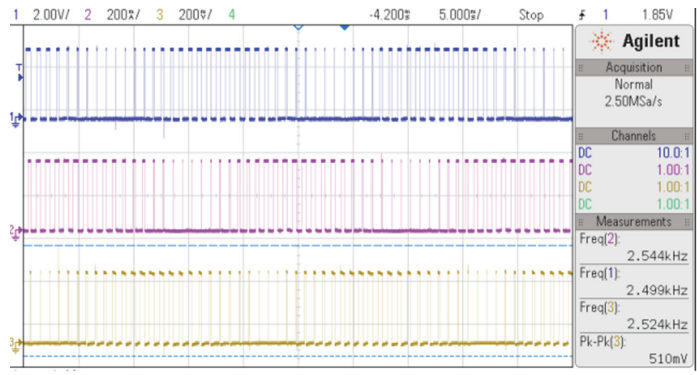

(c)

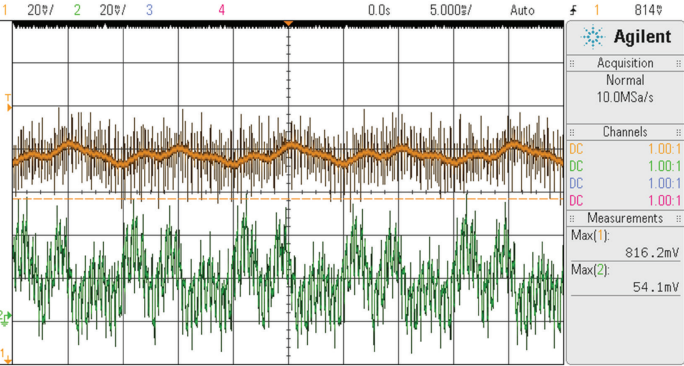

(b)

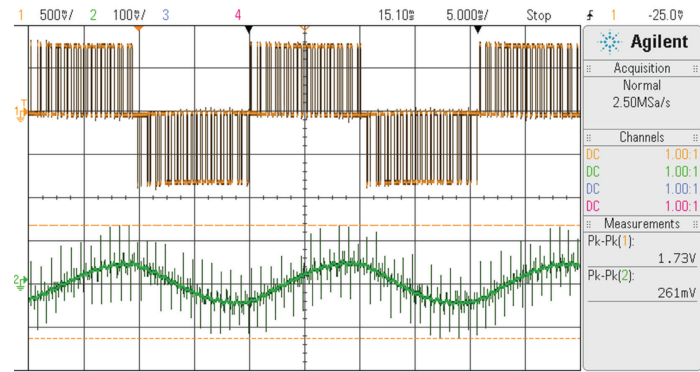

(d)

FIGURE 14: Hardware results from DSP showing (a) input voltage (ph-ph) and current (R-Phase), (b) DC link voltage and current, (c) PWM pulses for 3 legs of inverter from DSP, and (d) output voltage (ph-ph) and current (R-phase).

system model utilizing AC-DC-AC topology listed previously are closely matched with its Simulink reference offline results.

\section{Real-Time Implementation Using DSP}

The given system model is implemented in MATLAB mfile coding and also in real-time hardware setup using the DSP-MATLAB interface. PWM are pulses for hardware and MATLAB model generated using DSP processor 2. ePWM module is used to generate six pulses at a time from ePWM pins of DSP. These pulses are being fed to optocoupler TLP 250 which boosts up the voltage level to an extent at which IGBT switches can be triggered. At the same time, another processor is used to run the mathematical model of drive system as per decoupled method.

Figure 11 represents the block diagram of the hardware setup. As per specifications given in Appendix A, two Semikron make IGBT IPM module-based inverters used for this purpose, one acts as a rectifier and the other is used as an inverter to drive induction motor. Pulses from DSP2 are given to the Semikron inverter module 2 through the optoisolator ICs in order to strengthen the gate drive signal. The PWM logic is developed in Simulink model, and Figure 12 shows the logic generation of bipolar PWM for three-phase inverter. Comparative results are obtained for the input ph-ph voltage of diode rectifier and input phase current as shown in Figures 13(a) and 14(a). Figures 13(b) and 14(b) show DC link voltage and current waveforms.

The PWM pulses generated at the output of the optoisolator are shown in Figure 14(c) and those from the simulation are shown in Figure 13(c). In Figure 14, all voltage waveforms are phase-phase voltages with the multiplier setting of 200 , and all current waveforms are phase A current waveforms with the probe setting at $10 \mathrm{mV} / \mathrm{A}$. Figures 13 and $14(\mathrm{~d})$ reveal that the output voltage between two phases and phase currents is closely matched with that of the offline simulation results. As per analytical calculations as well as simulation and hardware results, the output RMS voltage obtained across the load is $85 \mathrm{~V}$. All the parameters are matched except for the grid voltage and current, since it has been assumed as the ideal source in simulation model, and real grid conditions in the laboratory are ignored. But in practical situations, the grid could be connected to transformers and many other loads in the laboratory building.

\section{Conclusion}

A new research platform for power electronics and drive system modelling using decoupled analytical method has been verified both in offline simulation and in real-time hardware. The $\mathrm{m}$-file program developed for state-space method-based electrical drive model accurately matching with hardware model. The same model has been validated using eZdsp processors with one as plant and the other as a controller. Decoupled method makes it easier with better accuracy and less calculation time which results in fast execution speed. This can be further extended to test the same with reduced order induction motor model, and results can be compared with existing results in order to further improvise the real-time model accuracy and its execution time. The results obtained from this work suggest that the developed models using the proposed method can be used as a research platform and extended to any complex power electronic applications. The obtained model is flexible and it can be extended to any system with different size (system order). These models can be used as user defined/function 
TABLE 3: Load specification: three-phase induction motor.

\begin{tabular}{lcl}
\hline Parameter & Value & Description \\
\hline $\mathrm{kVAbase}$ & $4 \mathrm{e} 3$ & Rated kVA of the machine \\
Vbase & 400 & Rated voltage $(\mathrm{L}-\mathrm{L})$ in $(\mathrm{V})$ \\
$\mathrm{Vm}$ & $231 * \sqrt{2}$ & Peak value of AC source voltage $(\mathrm{V})$ \\
$f$ & 50 & Rated frequency in $\mathrm{Hz}$ \\
$\omega$ & $2 * \mathrm{pi} * 50$ & Rated angular frequency in rad/s \\
$\mathrm{Rs}$ & 1.405 & Stator resistance in $\Omega$ \\
$\mathrm{Ls}(\mathrm{Lls}+\mathrm{Lm})$ & 0.178039 & Stator inductance in $\mathrm{H}$ \\
$\mathrm{Rr}$ & 1.395 & Rotor resistance in $\Omega$ \\
$\mathrm{Lr}(\mathrm{Llr}+\mathrm{Lm})$ & 0.178039 & Rotor inductance in $\mathrm{H}$ \\
$\mathrm{Lm}$ & 0.1722 & Stator-rotor mutual inductance in H \\
$h$ & 100 & Time step in $\mu$ s \\
$n$ & 9 & Carrier frequency $n$ times $50 \mathrm{~Hz}$ \\
$J$ & 0.0131 & Inertia of the machine in $\mathrm{kg} / \mathrm{m}^{2}$ \\
$B$ & 0.01841 & Friction coefficient in Nms $/ \mathrm{rad}$ \\
$p$ & 2 & No. of pole pairs \\
\hline
\end{tabular}

blocks to test with real-time processor/controller for future research work.

\section{Appendices}

\section{A. Three-Phase IGBT-Based Inverter (Semikron Make)}

IGBT module used: SKM75GB123D

DC link capacitor: $4700 \mu \mathrm{F}$

Gate driver: SKYPER 32 PRO

$V_{\mathrm{dc}}$ input: $800(\mathrm{~V})$

$V_{\mathrm{ac}}$ output: $415(\mathrm{~V})$

$I_{\mathrm{ac}}$ output: $20(\mathrm{~A})$

Output frequency: $50 \mathrm{~Hz}$

Switching frequency: $10 \mathrm{kHz}$

Type of cooling: force air cooled

Temp: $35^{\circ} \mathrm{C}$

Duty class: class I.

\section{B.}

For more details see Table 3.

\section{References}

[1] P. Livinti and R. Pusca, "Control of an electric drive system in the LabVIEW programming environment," in Proceedings of the 9th International Conference on Remote Engineering and Virtual Instrumentation (REV), pp. 1-6, Bilbao, Spain, July 2012.

[2] R. Champagne, L. A. Dessaint, and H. Fortin-Blanchette, "Realtime simulation of electric drives," Mathematics and Computers in Simulation, vol. 63, no. 3-5, pp. 173-181, 2003.
[3] H. Eren and C. C. Fung, "Virtual instrumentation of electric drive systems for automation and testing," in Proceedings of the 17th IEEE Instrumentation and Measurement Technology Conference (IMTC '00), vol. 3, pp. 1500-1505, May 2000.

[4] R. Champagne, L. Dessaint, G. Sybille, and B. Khodabakhchian, "Approach for real-time simulation of electric drives," in Proceedings of the Canadian Conference on Electrical and Computer Egineering (CCECE '00), vol. 1, pp. 340-344, May 2000.

[5] C. Bordas, C. Dufour, and O. Rudloff, "A 3-level neutralclamped inverter model with natural switching mode support for the real-time simulation of variable speed drives," in Proceedings of the International Symposium on Advanced Electromechanical Motion Systems, pp. 1-8, Lille, France, 2009.

[6] A. Myaing and V. Dinavahi, "FPGA-based real-time emulation of power electronic systems with detailed representation of device characteristics," IEEE Transactions on Industrial Electronics, vol. 58, no. 1, pp. 358-368, 2011.

[7] J. H. Allmeling and W. P. Hammer, "PLECS—-piece-wise linear electrical circuit simulation for Simulink," in Proceedings of the IEEE International Conference on Power Electronics and Drive Systems (PEDS'99), vol. 1, pp. 355-360, July 1999.

[8] S. Venugopal and G. Narayanan, "Design of FPGA based digital platform for control of power electronics systems," in Proceedings of the National Power Electronics Conference, pp. 1250-1255, December 2005.

[9] K. Jayalakshmi and V. Ramanarayanan, "Real-time simulation of electrical machines on FPGA platform," in Proceedings of the India International Conference on Power Electronics (IICPE '06), pp. 259-263, Chennai, India, December 2006.

[10] R. Krishnan, Electric Motor Drives: Modeling, Analysis, and Control, Pearson Education Asia, 2007. 

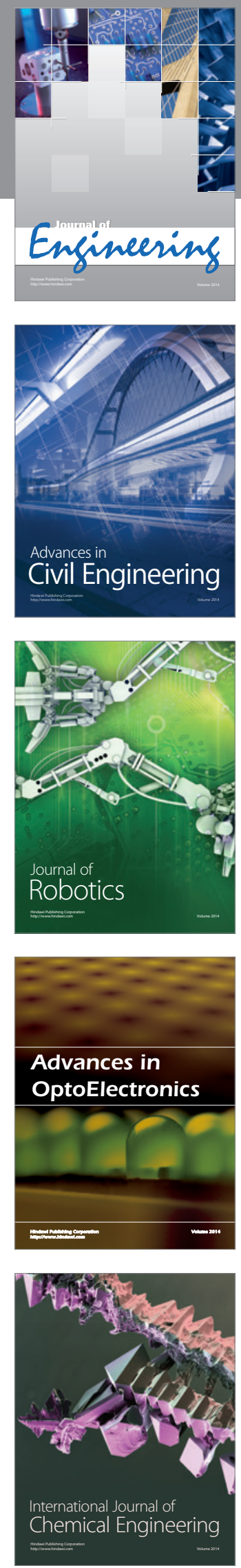

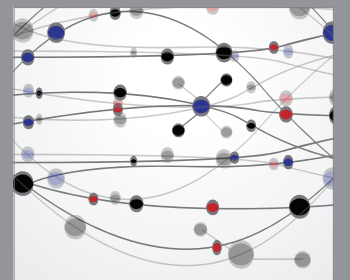

The Scientific World Journal
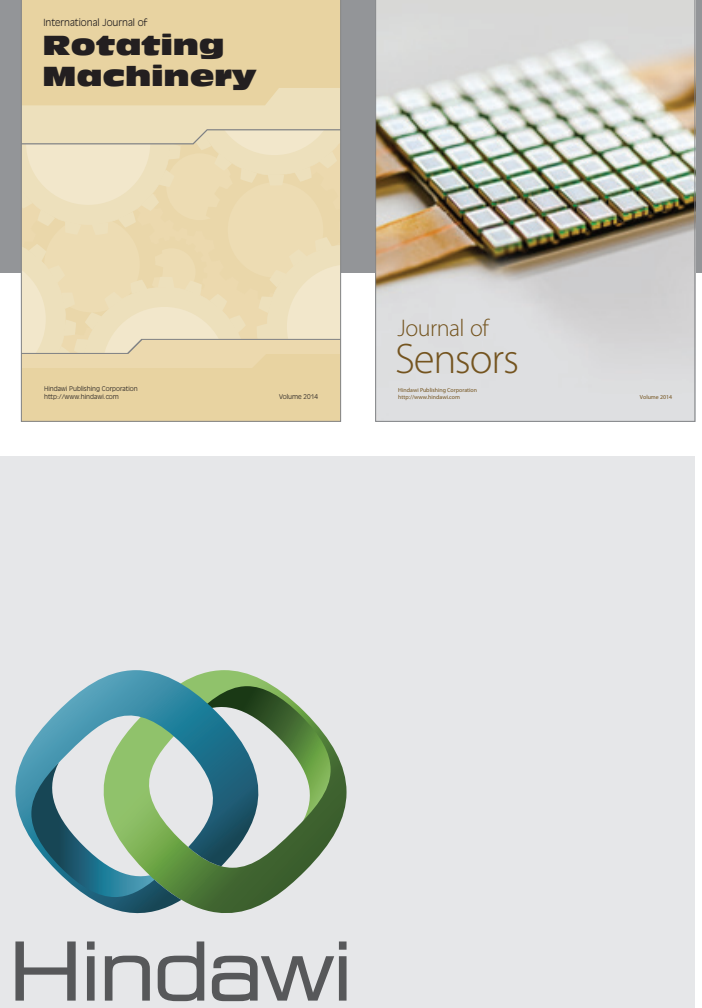

Submit your manuscripts at http://www.hindawi.com
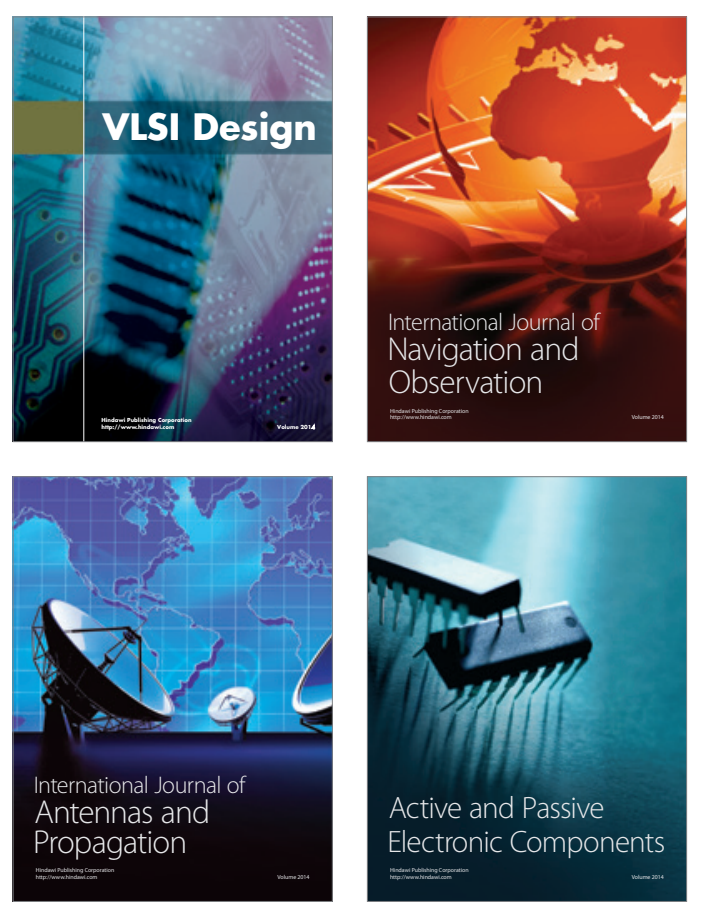
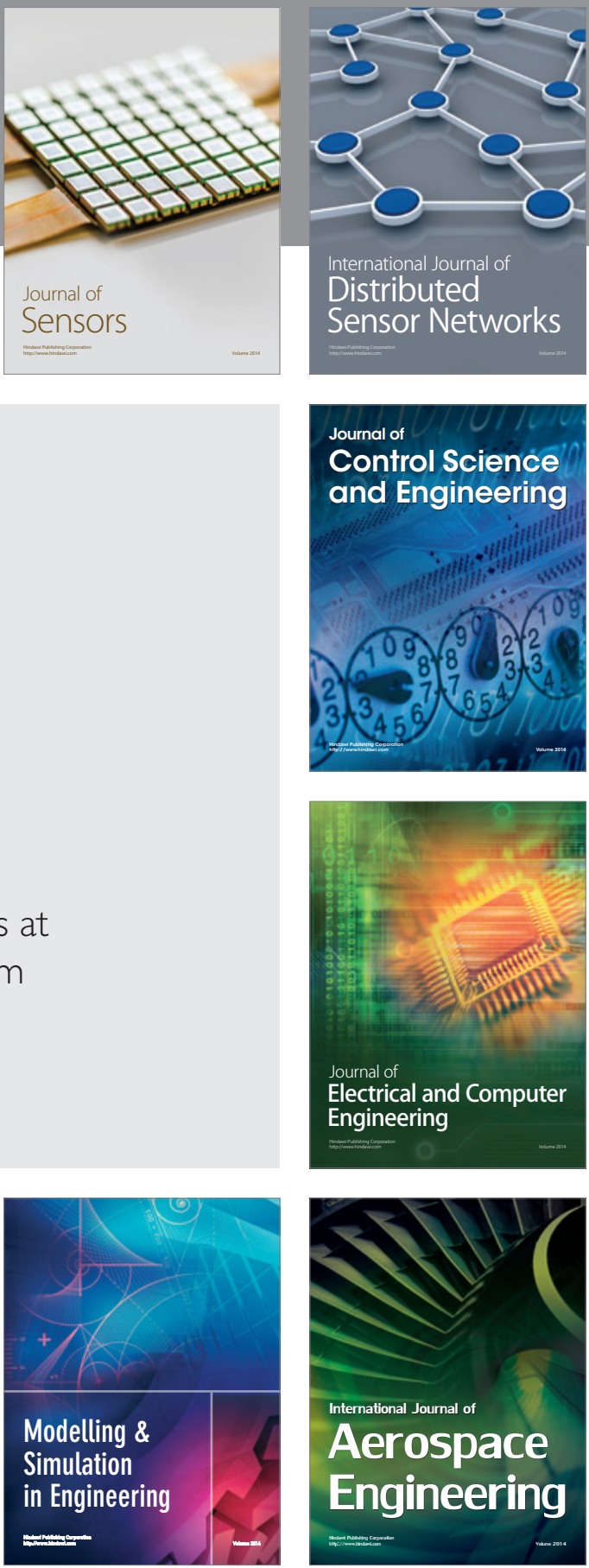

Journal of

Control Science

and Engineering
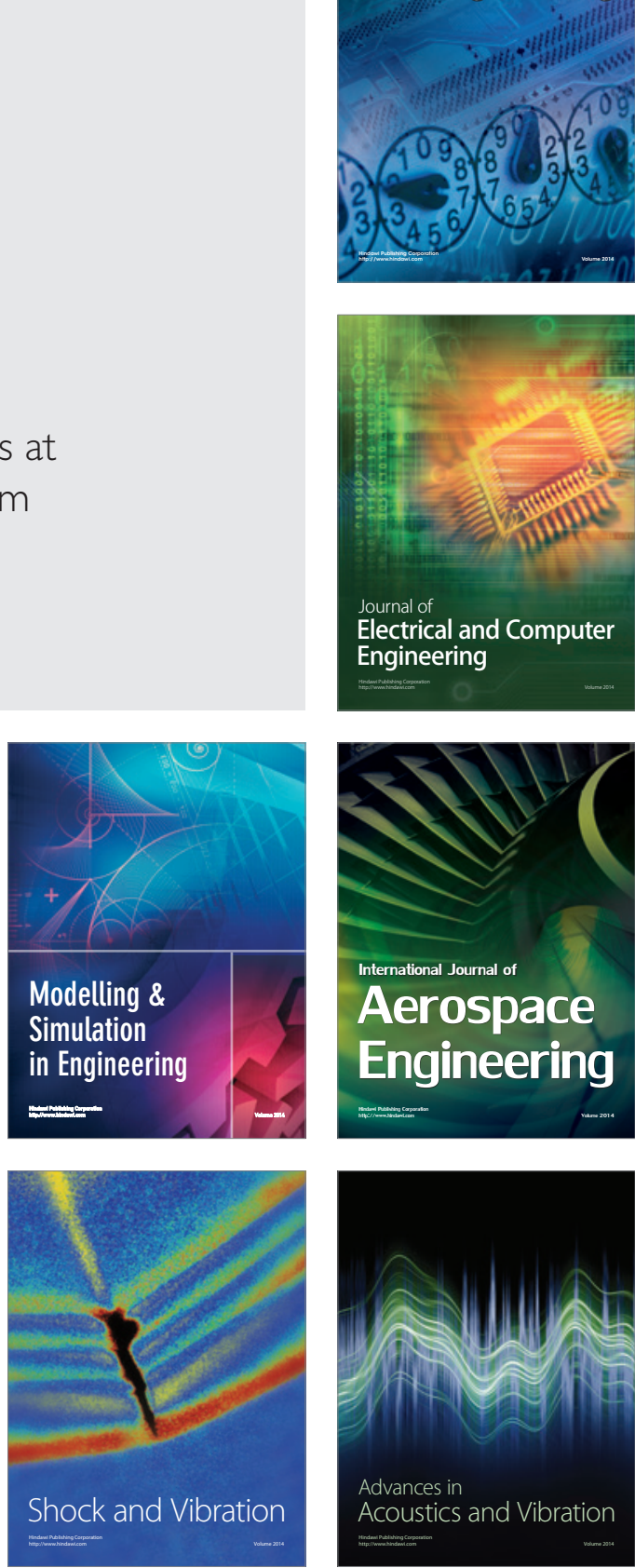